\title{
Letter to the Editor: Misquoting the ASD Prevalence Rate for Hong Kong: Comment on Tse (2020)
}

\author{
Hannah M. Y. Tse ${ }^{1}$ (D)
}

Accepted: 3 January 2021 / Published online: 22 January 2021

(c) The Author(s), under exclusive licence to Springer Science+Business Media, LLC part of Springer Nature 2021, corrected publication 2021

Tse (2020) noted in the introduction of his paper, "The most recent ASD prevalence rate reported for Hong Kong is 1 in 68 children and the rate is expected to increase (Centre for Disease Control and Prevention, HKSAR 2012)." The corresponding citation was "Centre for Disease Control and Prevention, HKSAR (2012). Identified prevalence of autism spectrum disorder. Retrieved May 28, 2019, from https:// www.cdc.gov/ncbddd/autism/data.html."

The cited webpage "www.cdc.gov" is indeed directed to the Centers for Disease Control and Prevention of the United States of America. As there is no Centre for Disease Control and Prevention in Hong Kong, quoting information from the webpage and presenting them as data from Hong Kong is something factually inaccurate.

According to the information retrieved from the cited link on October 28, 2020 (Centers for Disease Control and Prevention 2020), the reported prevalence data was collected from the Autism and Developmental Disabilities Monitoring Network, which consisted of 11 sites in the United States. Hence, the ASD prevalence reported in the cited link was for the US instead of Hong Kong.

To my best knowledge, there is no official ASD prevalence rate in Hong Kong. One frequently cited figure for Hong Kong was from the epidemiological study by Wong and Hui (2008) (e.g. Sun et al. 2013; Tait et al. 2016). Using the population statistics from Hong Kong government between 1986 and 2005, they reported "the prevalence was 16.1 per 10,000 children less than 15 years old", that is, 1 in 621 children, are diagnosed with ASD.

The current prevalence rate would likely be higher than 1 in 621 children, as according to the Education Bureau in Hong Kong, the number of students diagnosed with ASD has increased rapidly (The Government of the Hong Kong

Hannah M. Y. Tse

hannah-tse@hku.hk

1 Department of Psychology, The University of Hong Kong, Pokfulam Road, Hong Kong, China
Special Administrative Region 2019). However, as far as I know, we do not have a more updated and reliable prevalence rate in Hong Kong yet.

While the above misquote did not affect the conclusion of the paper, I would like to clarify that as without an official prevalence rate in Hong Kong, such misquote may lead to further misreporting by the research community.

Author Contributions HT wrote the manuscript.

\section{References}

Centers for Disease Control and Prevention. (2020). Data and Statistics on Autism Spectrum Disorder I CDC. Retrieved October 28, 2020, from Centers for Disease Control and Prevention website: https:// www.cdc.gov/ncbddd/autism/data.html.

Sun, X., Allison, C., Matthews, F. E., Sharp, S. J., Auyeung, B., Baron-Cohen, S., \& Brayne, C. (2013). Prevalence of autism in mainland China, Hong Kong and Taiwan: A systematic review and meta-analysis. Molecular Autism, 4, 7. https://doi. org/10.1186/2040-2392-4-7.

Tait, K., Fung, F., Hu, A., Sweller, N., \& Wang, W. (2016). Understanding Hong Kong Chinese families' experiences of an autism/ASD diagnosis. Journal of Autism and Developmental Disorders, 46(4), 1164-1183. https://doi.org/10.1007/s10803-015-2650-z.

The Government of the Hong Kong Special Administrative Region. (2019). EDB to enhance support for students with autism spectrum disorders. Retrieved October 29, 2020, from https://www. info.gov.hk/gia/general/201910/03/P2019100300291.htm?fontS ize $=1$.

Tse, A. C. Y. (2020). Brief report: Impact of a physical exercise intervention on emotion regulation and behavioral functioning in children with autism spectrum disorder. Journal of Autism and Developmental Disorders, 50(11), 4191-4198. https://doi.org/10.1007/ s10803-020-04418-2.

Wong, V. C. N., \& Hui, S. L. H. (2008). Epidemiological study of autism spectrum disorder in China. Journal of Child Neurology, 23(1), 67-72. https://doi.org/10.1177/0883073807308702.

Publisher's Note Springer Nature remains neutral with regard to jurisdictional claims in published maps and institutional affiliations. 